\title{
Correction to: No evidence of improved efficacy of covered stents over uncovered stents in percutaneous palliation of malignant hilar biliary obstruction: results of a prospective randomized trial
}

\author{
Elisabeth Dhondt ${ }^{1}$ (D) $\cdot$ Peter Vanlangenhove ${ }^{1} \cdot$ Karen Geboes $^{2} \cdot$ Lisbeth Vandenabeele $^{3} \cdot$ Lien Van Cauwenberghe $^{1} \cdot$ \\ Luc Defreyne $^{1}$
}

Published online: 6 July 2020

(C) European Society of Radiology 2020

Corretion to: European Radiology (2020) 30:175-185

https://doi.org/10.1007/s00330-019-06374-7

On request from the Editors, the authors would like to clarify the following:

the patient cohorts in the publications "No evidence of improved efficacy of covered stents over uncovered stents in percutaneous palliation of malignant hilar biliary obstruction: results of a prospective randomized trial" (Dhondt et al, https://doi.org/10.1007/s00330-019-06374-7) and "No Advantage of Expanded Polytetrafluoroethylene and Fluorinated Ethylene Propylene-Covered Stents over Uncovered Nitinol Stents for Percutaneous Palliation of

Malignant Infrahilar Biliary Obstruction: Results of a SingleCenter Prospective Randomized Trial" (Dhondt et al, https:// doi.org/10.1016/j.jvir.2019.07.013) have no overlaps.

Both were recruited from the hospital's cohort of all tumour patients referred for percutaneous transhepatic stenting who were not amenable by ERCP. In both publications, this was explained in the patients' recruitment flow chart.

Publisher's note Springer Nature remains neutral with regard to jurisdictional claims in published maps and institutional affiliations.

The online version of the original article can be found at https://oi.org/ 10.1007/s00330-019-06374-7

Elisabeth Dhondt

elisabeth.dhondt@uzgent.be

1 Department of Vascular and Interventional Radiology, Ghent University Hospital, C. Heymanslaan 10, 9000 Ghent, Belgium

2 Department of Gastroenterology, Ghent University Hospital, C. Heymanslaan 10, 9000 Ghent, Belgium

3 Department of Gastroenterology, Saint-Joseph Clinic Bornem and Willebroek, Bornem, Belgium 